\title{
Комплексные исследования продовольственного рынка Луганской области как составляющая международного сотрудничества по восстановлению Донбасса
}

\author{
Вячеслав Чеботарев \\ Михаил Суворов ** \\ Егор Чеботарев ${ }^{\star \star \star}$
}

Streszczenie: Przedstawiono wyniki kompleksowych badań marketingowych dotyczących aktualnego stanu rynku żywności w regionie Ługańskim na Ukrainie, ujawniono treść jego głównych problemów, a wnioski dotyczące ich rozwiązania są uzasadniane przy pomocy organizacji międzynarodowych.

Słowa kluczowe: zintegrowane badania marketingowe, Ukraina, region Ługański, regionalny rynek żywności, współpraca międzynarodowa.

\section{Введение}

Постановка проблемы. Преодоление последствий гибридной агрессии против Украины в Донбассе в экономической сфере возможно лишь при условии разработки системы научно-практических мер, направленных на обеспечение эффективной производственно-коммерческой деятельности

\footnotetext{
* Ługański Państwowy Uniwersytet im. T. Szewczenki, Ukraina.

** Właściciel firmy Foresplus, Ukraina.

${ }^{\star \star \star}$ Ługański Państwowy Uniwersytet im. T. Szewczenki, Ukraina.
} 
в Луганской и Донецкой областях украинских субъектов хозяйствования. Разработку такой системы мер целесообразно начинать с территорий Луганщины и Донетчины, которые контролируются Украиной в современных условиях. В последующем такая система мер, пусть и с определенными корректировками, вполне может быть реализована в Донбассе в целом.

Реальность такова, что в силу масштаба потерь и многообразных форм их проявлений Украина самостоятельно не в состоянии обеспечить преодоление последствий войны. Для этого будет необходима всесторонняя и объемная помощь международного сообщества. Однако, подобного рода сотрудничество может начинаться только при наличии в Украине таких детально проработанных мер, сведенных в четкие и прозрачные Проекты и Программы, с необходимыми производными механизмами реализации.

Исходя из хозяйственной структуры контролируемого Украиной регионального подкомплекса Луганской области, он имеет особо выраженную агропродовольственную направленность. Поэтому, вполне логично, что обоснование соответствующих научно-практических мер должно основываться на маркетинговых исследованиях регионального продовольственного рынка.

1. Уровень разработанности анализируемой проблемы в украинской экономической науке. Проблема маркетинговых исследований в продовольственной сфере регионов в целом уже получила определенную разработку в трудах Н. Бутенко ${ }^{1}$, А. Варченко ${ }^{2}$, В. Ратынского ${ }^{3}$. Приходится отметить нехватку прикладных практических разработок, в которых анализируются вопросы прогнозирования развития региональных рынков и соответствующего инструментария. В этом отношении можем назвать лишь работу Р. Окрепкого 4 .

Однако, подобного рода анализ состояния продовольственных рынков Луганщины и Донетчины в условиях войны только начинает формироваться. Он основывается на первых обобщающих исследованиях проблем социально-экономического развития современного Донбасса, авторами которых являются как целые исследовательские коллективы под руководством В. Горбулина ${ }^{5}$

1 Н. В. Бутенко, Особливості маркетингових досліджень на промисловому ринку, Вісник Академії праці і соціальних відносин Федерації професійних спілок України, Академія праці і соціальних відносин Федерації професійних спілок України, Київ 2010, № 2 (54), с. 56-62.

2 О. М. Варченко, Методичні підходи до дослідження ринкової кон'юнктури регіональних продовольчих ринків, «Актуальні проблеми економіки» 2008, № 12, с. 11-19.

3 В. В. Ратинський, Особливості маркетингових досліджень на ринку товарів промислового призначення, «Інноваційна економіка» 2013, № 6, с. 229-234.

4 Р. Б. Окрепкий, Тактичне прогнозування попиту як інструмент подолання диспропорцій у виробництві та споживанні продукції підприємства, «Економічний аналіз» 2014, Том 18, № 2, с. 188-194.

5 Донбас і Крим: ціна повернення: монографія, за заг. ред. В. П. Горбуліна, О. С. Власюка, Е. М. Лібанової, О. М. Ляшенко, НІСД, Київ 2015, 474 с. 
и Э. Либановой ${ }^{6}$, так и отдельные отечественные ученые: Н. Кисиль ${ }^{7}$, А. Колосов ${ }^{8}$, В. Чеботарев ${ }^{9}$. Однако, следует учитывать достаточно широкий спектр подобных подходов и оценок. Поэтому, всяческой поддержки заслуживает предложение группы ученых Института экономики промышленности НАН Украины под руководством А. Амоши по разработке Концепции государственной целевой Программы по восстановлению и развитию мира в восточных регионах Украины с представлением соответствующего обоснованного проекта ${ }^{10}$.

Целью данной статьи является отражение выводов проведенного комплексного маркетингового исследования продовольственного рынка Луганской области и последующего обоснования предложений международным благотворительным организациям по разработке и реализации их грантовой политики в оказании помощи по преодолению последствий войны в агропродовольственной сфере Донбасса.

Общей методической основой данного исследования стала диалектика. Из конкретных методов познания в наибольшей степени использовались: методы единства анализа и синтеза, единства логического и исторического, единства индукции и дедукции; совокупность экономико-математических методов (группировка, подстановок, экстраполяции) системно-структурного анализа.

Исходной информационно-аналитической основой исследования стали фундаментальные положения науки экономики и маркетинга; материалы Министерства по вопросам временно оккупированных территорий Украины, Государственной службы статистики Украины и Главного управления статистики в Луганской области; материалы международных благотворительных организаций по ликвидации последствий войны в Донбассе, а также лично собранные и обработанные авторами материалы маркетингового исследования потребительских предпочтений покупателей товаров продовольственного назначения Луганской области.

2. Изложение основного материала. На базе разработки теоретико-методологических и научно-практических посылок исследования и эмпири-

6 Політика інтеграції українського суспільства в контексті викликів та загроз подій на Донбасі (національна доповідь), [Лібанова Е.М., Горбулін В.П., Пирожков С.І. та ін.]; за ред. Е. М. Лібанової, НАН України, Київ 2015, 363 с.

7 Кісіль М. І., Інвестиційні проблеми в сільському господарстві Донбасу, «Економіка АПК» 2016, № 2, с. 79-83.

8 А. М. Колосов, Економічна блокада підприємств непідконтрольної частини Донбасу дає свої негативні наслідки, «Економічний вісник Донбасу» 2017, № 3, с. 4-10.

9 В. Чеботарьов, Чверть століття українсько-американської дружби: допомога Mеrсу Corps як модель міжнародної співпраці у подоланні наслідків військового конфлікту на Донбасі, Вип. 16, Агора 2016, с. 37-41.

10 Проект Концепції державної цільової Програми з відновлення та розбудови миру у східних регіонах України, О. І. Амоша, О. Ф. Новікова, В. П. Антонюк та ін., «Економічний вісник Донбасу» 2016, № 1 (43), с. 4-15. 
ческих основ, качестве исходного понимания главной категории можем привести следующее определение понятия «маркетинговые исследования региональных продовольственных рынков». Это - система сбора, обработки и анализа совокупности научно-практических данных и материалов по маркетинговой ситуации на региональных продовольственных рынках для обоснования адекватных рынкам маркетинговых мероприятий и решений в достижения заданного коммерческого и/или социально-экономического эффекта.

Проблема маркетинговых исследований региональных продовольственных рынков по своему содержанию и инструментарию разработки является сложной междисциплинарной проблемой. В общем понимании она определяется уровнем развития производительных сил и производственных отношений той или иной страны, местом и ролью в ее структуре национального хозяйства агропродовольственного комплекса и особенностями административно-территориального устройства данной страны.

Становление и утверждение в Украине системы рыночных отношений, определяющая роль агропродовольственного комплекса в структуре экономики и наличие качественно определенных административно-территориальных единиц областного и межрегиональных уровней постепенно на повестку дня разработок украинских ученых и специалистов-практиков выдвинули вопросы маркетинговых исследований региональных продовольственных рынков. При этом следует реально представлять, что в Украине существует ряд факторов, которые объективно тормозят разработку данной проблемы.

Среди них наиболее значимыми являются:

- ненасыщенный, в целом - дефицитный характер рынка продовольственной продукции как на общегосударственном, так и региональных уровнях;

- низкий (по сравнению с развитыми странами) уровень жизни подавляющего большинства населения страны и, как следствие, несформированный рынок потребителя;

- доминирующее положение на украинском агропродовольственном рынке мощных иностранных производителей и / или поставщиков, имеющих современный развитый маркетинг и затрудняющих (хотя, в неявных формах) маркетинговую деятельность украинских субъектов рынка и в целом - высокая зависимость внутреннего продовольственного рынка от мировых товарных и финансовых рынков.

Преодоление последствий войны в Донбассе возможно лишь при условии непосредственной деятельности в этом направлении всех граждан Украины. Но в первую очередь это по понятным причинам касается граждан самого Донбасса. 
Считая данное положение априорной истиной и используя соответствующий опыт международного сотрудничества, к этому подключились преподаватели и студенты кафедры экономической теории, маркетинга и предпринимательства ГУ «Луганский национальный университет имени Тараса Шевченко» (Старобельск), а также заинтересованные представители бизнеса.

В течение 2015-2017 гг. на базе кафедры с привлечением преподавателей других высших учебных заведений функционировал коммуникационно-консультационный центр и экспертно-консультационная группа одной из ведущих международных неправительственных благотворительных организаций мира Mercy Corps (eе ресурсной и организационно-экономической основой является США). По итогам реализации организацией Mercy Corps программы «Самозанятость» при научно-практическом сопровождении кафедры в Луганской и Донецкой областях было предоставлено 1750 грантов по 500 долл. США (главным образом для переселенцев). Благодаря этому в сфере микропредпринимательства и малого и среднего бизнеса двух регионов было создано более 300 новых рабочих мест. И это - лишь один из социально-экономических эффектов деятельности Mercy Corps и кафедры по преодолению последствий войны в Донбассе.

Была сформулирована идея проведения комплексного маркетингового исследования продовольственного рынка Луганской области и на этой базе - обоснование для международных инвесторов предложений по определению приоритетных направлений, форм и объемов благотворительной помощи в производственно-коммерческой цепочке «региональный производитель - торговля - конечный потребитель» на территории, контролируемой Украиной. Механизмами проведения указанного исследования стали три в определенной степени обособленных, но соподчиненных и взаимодополняющих исследования.

В этом был активно использован опыт польских ученых-практиков факультета менеджмента Лодзинского университета ${ }^{11}$, вместе с которыми кафедрой в 2016 г. был основан Центр научно-исследовательского сотрудничества.

Первое - сфера рынка business-to-business. Анализ и оценка потенциальных возможностей и соответствующих ресурсных потребностей производителей товаров продовольственного назначения Луганской области в сфере малого и среднего бизнеса по увеличению объемов и расширению ассортимента данной продукции (неотъемлемой составляющей при этом было определение перспектив создания новых рабочих мест на Луганщине).

Второе - сфера business-to-business. Анализ и оценка перспектив торговых предприятий независимо от организационно-правовых форм и разме-

11 А. М. Колосов, Економічна блокада підприємств непідконтрольної частини Донбасу дає свої негативні наслідки, «Економічний вісник Донбасу» 2017, №3, с. 4-10. 
ров бизнеса, функционирующих в регионе по увеличению объемов реализации продовольственной продукции региональных производителей.

Третье - сфера рынка business-to-business. Анализ и оценка предпочтений потребителей-конечных покупателей области по покупке товаров продовольственного назначения региональных производителей.

Методическое обеспечение реализации отмеченного комплексного исследования составили три отдельные анкеты (в соответствии с указанными составляющими), разработанные преподавателями кафедры и заинтересованными представителями бизнеса региона. Данные анкеты содержали перекрестные вопросы для каждой группы респондентов по определенным направлениям маркетинга и производства товаров продовольственного назначения. Кроме анкет по первому и второму компонентами дополнительно были разработаны еще и опросники для проведения личных углубленных интервью (соответственно для товаропроизводителей и руководителей торговых предприятий). Анкетированием и дополнительными опросами-интервью по трем приведенным исследованиями-компонентами были охвачены все 12 административно-территориальных районов Луганской области, которые контролируются Украиной.

Учитывая сложность каждого из исследований-компонентов, первое и второе из них проводили только преподаватели кафедры и предприниматели. Третье исследование (а также - экономико-математическое обработки собранного материала по первым двум компонентам) под руководством преподавателей осуществляли студенты.

Анкетирование с целью анализа и оценки предпочтений потребителей-конечных покупателей товаров продовольственного назначения осуществлялось по анкете, которая содержала 14 вопросов (преимущественно в открытой форме) с количеством возможных вариантов ответов от 3 до 7. Оно проводилось студентами методом личного интервью в местах купли-продажи продовольственных товаров, а также с посещением студентами-интервьюерами покупателей непосредственно по месту их проживания и/или по месту работы.

Для обеспечения объективности и репрезентативности выводов маркетингового исследования большое внимание было уделено определению его выборки. После обработки нескольких подходов за основу была взята методика, специально разработанная для исследований именно продовольственного рынка ${ }^{12}$. Согласно данной методике, расчет выборки осуществлялся по формуле:

$$
S S=\frac{Z^{2} \times(p) \times(1-p)}{c^{2}}
$$

12 В. Чеботарьов, Чверть століття українсько-американської дружби: допомога Меrсу Corps як модель міжнародної співпраці у подоланні наслідків військового конфлікту на Донбасі, Вип. 16, Агора 2016, с. 37-41. 
где:

$\mathrm{Z}$ - фактор (для 95\%);

p - процент заинтересованных респондентов или ответов;

c - доверительный интервал в десятичной форме.

При этом, генеральную совокупность, в данном случае, количество населения на территории Луганской области, контролируемой Украиной, было рассчитано как количество постоянного населения данной территории и количество переселенцев, которые реально проживают в местах официальной регистрации. То есть, была предпринята попытка недопущения искусственного завышения генеральной совокупности за счет лиц, которые являются зарегистрированными, однако не проживают на подконтрольной территории (прежде всего, речь идет о субъектах «пенсионного туризма»). Для этого были использованы материалы Министерства по вопросам временно оккупированных территорий и внутренне перемещенных лиц ${ }^{13}$.

Рассчитанный объем выборки исследования потребительских предпочтений конечных покупателей товаров продовольственного назначения (сфера business-to-customer) составил 475 человек.

Для обеспечения репрезентативности выборки, доли (удельный вес) различных категорий анкетируемых покупателей (кроме удельного веса реально проживающих переселенцев на контролируемой Украиной территории) соответствовали удельному весу жителей области, проживающих: в городах областного подчинения (Северодонецке, Рубежном, Лисичанске); в районных центрах; в поселках городского типа; в сельской местности. Удельный вес этих категорий жителей области рассчитывался на основе данных Главного управления статистики в Луганской области ${ }^{14}$.

По итогам проведенного маркетингового исследования нами было установлено, что в существенно большей мере покупатели области, по сравнению с привозными товарами продовольственного назначения из других регионов Украины и стран, предпочитают товары региональных производителей. Этот показатель несколько колеблется по выделенным товарным группам. Так, удельный вес покупателей, отдающих предпочтение местным овощам, фруктам и ягодам составляет около 72\%; молоку и молочным продуктам - 70\%; мясу и мясным продуктам - более 60\%. Однако, в целом, такое восприятие местных товаров продовольственного назначения характерно для всех выделенных групп потребителей: и по месту жительства, и по уровню благосостояния.

13 Проект Концепції державної цільової Програми з відновлення та розбудови миру у східних регіонах України, О. І. Амоша, О. Ф. Новікова, В. П. Антонюк та ін., «Економічний вісник Донбасу» 2016, № 1 (43), с. 4-15.

14 B. Glinkowska, B. Kaczmarek, Zarządzanie międzynarodowe i internacjonalizacja przedsiębiorstw. Teoria i praktyka, Wydawnictwo UŁ, Łódź 2016, s. 182-218. 
При этом, откровенно неожиданным оказался факт, что после трех с половиной лет жизни в условиях проведения антитеррористической операции около 75\% потребителей Луганщины сами себя идентифицируют как покупателей со средним уровнем благосостояния; $10 \%$ - как покупателей с высоким уровнем благосостояния и только 15\% - как граждан с низким уровнем благосостояния. Однако, приведенная самоидентификация покупателей получила достаточно наглядное подтверждение ответами респондентов на другие опосредованно уточняющие (и в определенной степени - завуалированные) вопросы анкеты. Первое: более 63\% покупателей главным фактором при покупке продовольственных товаров считают именно качество товаров и их удобную упаковку и фасовку (а не цену). По общепринятым в современной мировой маркетологии подходом для $80 \%$ населения с низким уровнем благосостояния преобладающим фактором при покупке товаров является цена, а не качество. Второе: оставаясь сторонниками местных продовольственных товаров, более 67\% покупателей их главным недостатком считают опять-таки качество (а не неконкурентоспособной цену, либо - другое по усмотрению анкетируемых).

Результаты исследования подтвердили ожидания, что для большинства отечественных покупателей главными местами покупки товаров продовольственного назначения остаются традиционные рынки-базары и магазины с продажей товаров по бывшей советской схеме - «через прилавок». Показательно, что даже в местах областного подчинения, где сосредоточены магазины нескольких ведущих торговых сетей Украины - «АТБ», «Сільпо», «Велика кишеня» и «Брусничка», а также несколько торговых сетей регионального уровня (и что характерно - даже для покупателей с высоким уровнем благосостояния) супермаркеты для 57\% покупателей, в лучшем случае, «занимают» только вторые-третьи позиции.

При этом, считаем необходимым учитывать следующий важный факт, который объективно «подталкивал» покупателей высказываться не в пользу супермаркетов: в современных условиях даже самая мощная и по количеству магазинов, и по объемам продаж торговая сеть в регионе (а таковая - «АТБ») развернула деятельность даже не во всех районных центрах области. Вместе с тем, ментальное тяготение потребителей Луганщины к прежним классических форм купли-продажи товаров - достаточно очевидно (это выступает распространенным и устойчивым явлением в целом для Украины).

Проведенное анкетирование показало наличие однозначных предпочтений покупателей области относительно склонности покупать товары-полуфабрикаты. По этому признаку сторонников таких продовольственных продуктов примерно столько же, сколько тех, кто предпочитает традиционное приготовление дел.

Покупатели Луганской области оказались крайне солидарными относительно нежелания за свой счет поддерживать местных производителей про- 
довольственных товаров. Таких желающих оказалось меньше 3\%, что в целом находится в пределах статистической погрешности.

Проведенное маркетинговое исследование покупателей товаров продовольственного назначения Луганской области подтверждает обобщающий вывод украинских ученых в отношении кризисного состояния агропродовольственного рынка страны. На фоне отдельных положительных явлений и тенденций, которые начали набирать силу в последние годы, в целом для агропродовольственного рынка Украины присущим является его глубинная структурная деформированность, зависимость от конъюнктуры мировых товарных и финансовых рынков, сырьевая направленность, недееспособность государственной регуляторной политики, снижение покупательной способности основных слоев населения.

Относительно агропродовольственного рынка Донбасса, в частности - контролируемой части Луганской области, отмеченные кризисные явления еще в большей степени усиливаются. Обработка собранных материалов исследования потребительских предпочтений покупателей (непосредственно - анкет, а также обобщение сопутствующих комментариев, сделанных покупателями в ходе анкетирования) является основой для классификации дополнительных проблем. Они в значительной степени сформировались в результате войны (или, - исключительно вследствие войны).

Первая. Существенное свертывание рынков сбыта агропродовольственной продукции для товаропроизводителей региона.

Друга. Ухудшение качества товаров товаропроизводителей региона (прежде всего, - товаров животного происхождения).

Третья. Существенное увеличение на региональном рынке удельного веса привозной продукции из других регионов Украины и других стран мира.

Четвертая. Усиление сырьевой направленности хозяйственной деятельности товаропроизводителей и, как следствие, - дефицитность местных товаров с высоким содержанием добавленной стоимости.

Пятая. Потеря объектов оптовой (мелко-оптовой) торговли продукцией и критическое состояние дорожного хозяйства (в том числе, - в результате интенсивного передвижения военной техники).

Обобщение классифицированных на основе проведенного исследования потребительских предпочтений покупателей товаров продовольственного назначения Луганской области дает основания отметить следующее.

Война в значительной степени трансформировала содержание и проблемы регионального продовольственного рынка. Его главный лимитирующий фактор, в отличие от других регионов Украины (за исключением Донецкой области, которая тоже пострадала от военной агрессии), фокусируется не в плоскости производства (хотя традиционным является также и недопотребление гражданами большинства продовольственных продуктов, и нерациональная структура питания в целом), а в плоскости чисто рыночных 
(сбытовых) проблем. Они сводятся к тому, где и как продать то, что производится (и может быть потенциально произведено). Другими, в современных условиях на Луганщине главная проблема заключается в инфраструктурном обеспечении регионального агропродовольственного рынка.

Согласно такого промежуточного вывода, можем обосновать направления, по которым благотворительная помощь иностранных инвесторов даст наибольший социально-экономический эффект в деле более быстрого и менее болезненного преодоления последствий войны. Это - ни что иное, как определение приоритетных блоков бизнес-идей в предоставлении Украине международной грантовой помощи, направленной на решение указанных проблем.

Теоретико-методологическим основанием разработки таких блоков бизнес-идей является соответствующая нормативно-правовая база Украины и предложения отечественных ученых по определению масштаба инвестиционной потребности в агропродовольственной сфере Донбасса для преодоления последствий войны, а также первые наработки в разработке «Плана Маршала для Украины» ${ }^{15}$.

В качестве таких приоритетных блоков выделим следующие.

1. Учреждение сельскохозяйственных обслуживающих кооперативов (и/или - бизнес-предприятий, которые бы выполняли их функции).

2. Создание межрайонных мелко-оптовых аграрных рынков-площадок.

3. Оборудование на базе Лисичанского предприятия ГП «Луганскстандартметрология» современной лаборатории по комплексной оценке сельскохозяйственного сырья и продовольственных продуктов на предмет соблюдения производителями норм и стандартов НАССР и содержания ГМО и техническая помощь районным службам фитосанитарного и ветеринарного контроля.

4. В производственной сфере приоритетом должно стать предоставление помощи по освоению переработки местной сельскохозяйственной продукции и производства пищевых продуктов с большим содержанием добавленной стоимости.

5. Создание структур дораднического типа по широкому кругу производственно-коммерческой деятельности в агропродовольственной сфере.

Отмеченные направления бизнес-идей следует рассматривать именно как приоритеты. Материалы проведенного исследования дают основания классифицировать их как своеобразные «точки роста» в агропродовольственной сфере региона. Первоочередная поддержка их реализации даст больший социально-экономический эффект для Украины и будет способствовать более

15 http://www.lg.ukrstat.gov.ua/ - офіційний сайт Головного управління статистики у Луганській області. 
эффективному использованию таких необходимых для Украины средств международного сообщества на преодоление последствий войны в Донбассе.

Выводы из проведенного анализа и перспективы дальнейшей разработки проблемы. Материалы и обобщающие рекомендации проведенного комплексного исследования агропродовольственного рынка Луганской области были представлены украинским и международным благотворительным организациям (International Seed Fund (США), FHI - 360 (США) и другим). Они получили высокую оценку потенциальных Доноров и приняты для разработки Проектов с целью оказания благотворительной помощи по восстановлению экономики Донбасса.

В качестве дальнейшей разработки проблемы авторами определены продолжение сотрудничества с потенциальными Донорами на предмет реального осуществления таких Проектов и их научно-практическое сопровождение.

\section{Библиография}

Бутенко Н. В., Особливості маркетингових досліджень на промисловому ринкy, Вісник Академії праці і соціальних відносин Федерації професійних спілок України, Академія праці і соціальних відносин Федерації професійних спілок України, Київ 2010, № 2 (54), с. 56-62.

Варченко О. М., Методичні підходи до дослідження ринкової кон'юнктури регіональних продовольчих ринків, «Актуальні проблеми економіки» 2008, № 12, c. 11-19.

Донбас і Крим: изна повернення: монограбія, за заг. ред. В. П. Горбуліна, О. С. Власюка, Е. М. Лібанової, О. М. Ляшенко, НІСД, Київ 2015, 474 с.

Кісіль М. І., Інвестиційні проблеми в сільському господарстві Донбасу, «Економіка АПК» 2016, № 2, с. 79-83.

Колосов А. М., Економічна блокада підприємств непідконтрольної частини Донбасу дає свої негативні наслідки, «Економічний вісник Донбасу» 2017, № 3, с. 4-10.

Кушнір Н. Б., Кузнєцова Т. В., Статистика: навч.-метод. посіб. для самост. вивчення дисиипліни, за ред. Н. Б. Кушнір, Т. В. Кузнєцової, НУВГП, Рівне 2008, 205 c.

Окрепкий Р. Б., Тактичне прогнозування попиту як інструмент подолання диспропориій у виробництві та споживанні продукиї підприємства, «Економічний аналіз» 2014, Том 18, № 2, с. 188-194.

Політика інтеграції украӥнського суспільства в контексті викликів та загроз подій на Донбасі (національна доповідь), [Лібанова Е.М., Горбулін 
В. П., Пирожков С. І. та ін.]; за ред. Е. М. Лібанової, НАН України, Київ 2015, 363 c.

Проект Концепиї державної иільової Програми з відновлення та розбудови миру у східних регіонах Украӥни, О. І. Амоша, О. Ф. Новікова, В. П. Антонюк та ін., «Економічний вісник Донбасу» 2016, № 1 (43), с. 4-15.

Ратинський В. В., Особливості маркетингових досліджень на ринку товарів промислового призначення, «Інноваційна економіка» 2013, № 6, с. 229-234.

Чеботарьов В., Чверть століття українсько-американської дружби: допомога Мегсу Corps як модель міжнародної співпраці у подоланні наслідків військового конфлікту на Донбасі, Вип. 16, Агора, 2016, с. 37-41.

Glinkowska B., Kaczmarek B., Zarządzanie międzynarodowe i internacjonalizacja przedsiębiorstw. Teoria i praktyka, Wydawnictwo UŁ, Łódź 2016, s. 290.

http://mtot.gov.ua/category/pro-ministerstvo/ - офіційний сайт Міністерства з питань тимчасово окупованих територій та внутрішньо переміщених осіб.

http://www.lg.ukrstat.gov.ua/ - офіційний сайт Головного управління статистики у Луганській області.

\title{
Complex studies of the food market Lugansk region as a component of international cooperation to restore the Donbass
}

\begin{abstract}
The results of the complex marketing research of the current state of the food market of the Lugansk region of Ukraine are covered, the content of its main problems is disclosed and proposals for their solution are substantiated using the assistance of international organizations.
\end{abstract}

Keywords: integrated marketing research, Ukraine, Lugansk region, regional food market, international cooperation. 